\title{
MR
}

\section{Angiotensin-converting enzyme gene polymorphism (insertion/deletion) and liver fibrosis in Turkish patients from the western Black Sea region, Turkey}

\author{
N.K. Turhan', S. Uygun Ilikhan ${ }^{2}$, A.C. Hamamcioglu ${ }^{3}$, Y. Ustundag ${ }^{2}$, A. Dursun 4 \\ and F. Kokturk ${ }^{5}$ \\ ${ }^{1}$ Internal Medicine Clinic, Ataturk State Hospital, Zonguldak, Turkey \\ ${ }^{2}$ Department of Internal Medicine; School of Medicine, Bulent Ecevit University, \\ Zonguldak, Turkey \\ ${ }^{3}$ Department of Biochemistry, Faculty of Pharmacy, Bulent Ecevit University, \\ Zonguldak, Turkey \\ ${ }^{4}$ Department of Medical Genetics, School of Medicine, Bulent Ecevit University, \\ Zonguldak, Turkey \\ ${ }^{5}$ Department of Statistics, School of Medicine, Bulent Ecevit University, \\ Zonguldak, Turkey \\ Corresponding author: A.C. Hamamcioglu \\ E-mail: achamamcioglu@beun.edu.tr \\ Genet. Mol. Res. 14 (4): 17079-17090 (2015) \\ Received August 7, 2015 \\ Accepted October 18, 2015 \\ Published December 16, 2015 \\ DOI http://dx.doi.org/10.4238/2015.December.16.8
}

\begin{abstract}
Chronic viral hepatitis B, chronic viral hepatitis C, nonalcoholic steatohepatitis, alcoholic liver disease, autoimmune hepatitis, primary biliary cirrhosis, and secondary biliary cirrhosis are important health issues worldwide. While an association between angiotensinconverting enzyme gene insertion/deletion (ACE gene I/D) polymorphism and liver fibrosis has been demonstrated in rat studies, the results of clinical studies area have been contradictory. The aim of this study was to assess the possible association between ACE gene I/D polymorphism
\end{abstract}


and liver fibrosis in a large group of Turkish patients from the western Black Sea region. In 418 patients with different etiologies, ACE gene I/D polymorphism and serum ACE levels were investigated. The distribution of the "DD", "ID", "II" genotypes of the ACE gene were 32.5, 48.8, and $18.7 \%$ in the mild to moderate fibrosis group ( $\mathrm{N}=246, \mathrm{~F}: 1-3$ according to Ishak's score) and 39.0, 44.2, and $16.9 \%$ in the advanced fibrosis group ( $N$ = 172, F:4-6 according to Ishak's score). A significant correlation between serum ACE levels and ACE gene alleles was identified $(P<0.001)$ : serum ACE levels of patients with $D$ alleles were higher than those of patients with I alleles [44 (min 7-max 101) versus 29 (min 7-max 96)]. Patients with advanced fibrosis were also found to be older than those with mild to moderate fibrosis $(P<0.001)$. No significant association was noted between the patient gender and fibrosis severity. We conclude that ACE I/D polymorphism is not associated with the degree of liver fibrosis.

Key words: Liver fibrosis; Angiotensin-converting enzyme; Gene polymorphism; Turkish population

\section{INTRODUCTION}

Chronic viral hepatitis $B(\mathrm{HBV})$, chronic viral hepatitis $\mathrm{C}(\mathrm{HCV})$, non-alcoholic steatohepatitis (NASH), alcoholic liver disease (ALD), autoimmune hepatitis $(A H)$, primary biliary cirrhosis (PBC), and secondary biliary cirrhosis (SBC) are important health issues worldwide. Some host factors play a pivotal role in the progression of liver fibrosis associated with these disorders and one such factor is Angiotensin II. Although the mechanism by which Angiotensin II exerts its effect on the progression of liver fibrosis is not completely understood, the pro-fibrotic effect of transforming growth factor beta 1 (TGF- $\beta 1$ ) is reportedly enhanced by Angiotensin II via an up-regulation of toll like receptor 4 (TLR4) (Li et al., 2013). Angiotensin-converting enzyme (ACE) is responsible from the turnover of Angiotensin I into Angiotensin II and although plasma levels of ACE remain constant in a single individual, plasma ACE levels differ between individuals. Depending on the presence (insertion [I]) or the absence (deletion [D]) of a 287-basepair nonsense DNA domain, ACE exists as one of three different genotypes: DD and II homozygous or DI heterozygous (Yuan et al., 2013). A study performed with different healthy individuals from the same family revealed that differences in ACE levels between individuals result from ACE gene I/D polymorphism. Individuals with D genotypes have been demonstrated to have more All than the ones with I genotypes (Rigat et al., 1990). It has been shown in several studies that the use of various ACE inhibitors or angiotensin receptor blockers in combination with interferon therapy can reduce the progression of liver fibrosis (Jonsson et al., 2001; Terui et al., 2002; Kurikawa et al., 2003). Although ACE gene expression has been shown to play a role in liver fibrosis in several experimental studies (Jonsson et al., 2001; Shahid et al., 2013), most clinical studies in this area have shown no significant association between ACE gene polymorphism and the stages of fibrosis in HCV, PBC, and NAFLD patients (Powell et al., 2000; Forrest et al., 2005; Oruç et al., 2008; Güçlü et al., 2010; Raslan et al., 2011). Fabris et al. (2009), on the other hand, suggested a relationship between gender and ACE gene I/D polymorphism: ACE I/I homozygote women had liver fibrosis scores five times higher than ACE D/D homozygote and ACE I/D heterozygote women. The DD genotype has furthermore been 
found to be significantly associated with hepatocellular carcinoma (HCC) risk; however, results in this area have been somewhat conflicting: Yuan (2013) found D allele frequencies to be lower in HCC patients than in controls, whereas Zha (2014) found D allele frequencies of HCC patients to be higher than those of controls. The studies carried out to investigate the relationship between ACE gene I/D polymorphism and/or serum ACE levels with liver fibrosis between the years of 2000 and 2015 have yielded conflicting conclusions, which could be attrinuted to the small sample sizes used (Table 1). The aim of this study was therefore to further investigate the association of ACE gene I/D polymorphism and/or serum ACE levels with liver fibrosis using a larger sample of study subjects than has previously been used. In the study, subjects with diverse hepatic diseases were furthermore included, while in each of the previous studies, patients with only one type of etiology for liver disease were investigated. This study was therefore an investigation into the possible effects of ACE gene I/D polymorphism and serum ACE levels on fibrosis grade in patients with liver fibrosis due to various diseases.

\section{MATERIAL AND METHODS}

\section{Patients}

A total of 418 patients from a Turkish population with a histopathological diagnosis of liver fibrosis and one of a number of underlying diseases such as HBV, HCV, NASH, ALD, $\mathrm{AH}, \mathrm{PBC}$, and SBC were enrolled in this study. Bulent Ecevit University Practice and Research Hospital Ethics Committee (2012-94-26/06) approved the study and written informed consent was obtained from each patient. The serological profiles and histopathological data for fibrosis stage and necroinflammatory scores were available in all cases. The medical records of all patients were evaluated and physical examinations were performed. In addition to routine biochemical tests, serum ACE levels and ACE gene polymorphisms were assessed for each patient.

\section{Identification of ACE gene polymorphisms}

Whole blood samples were taken from all patients and genomic DNA was extracted from these samples using a QIAamp DNA Mini Kit (Qiagen, Tokyo, Japan). The method described by Rigat et al. (1992) was used to identify ACE gene I/D polymorphism. The priers used in this assessment were 5' CTG GAG ACC ACT CCC ATC CTT TCT 3' (sense) and 5' GAT GTG GCC ATC ACA TTC GTC AGA 3' (antisense). Polymerase chain reaction (PCR) was performed according to Fabris et al. (2007), after which $5 \mu$ of the resulting PCR products were loaded on $1.5 \%$ agarose gel and visualized by ethidium bromide staining. Allele (I/D) types and genotype for each sample were determined based on the PCR product sizes.

\section{Serum ACE levels}

A method modified from that described by Cushman and Cheung (1971) and subsequently described by Lieberman (1975) was used to determine the activity of angiotensin-converting enzyme (ACE) from the sera of the study subjects. Hippuryl-L-histidyl-L-leucine was used as a substrate in the assay and units are described as nanomoles of hippuric acid liberated per minute per $\mathrm{ml}$ serum under standard assay conditions. Results are reported as $\mathrm{U} / \mathrm{mL}$. 
N.K. Turhan et al.

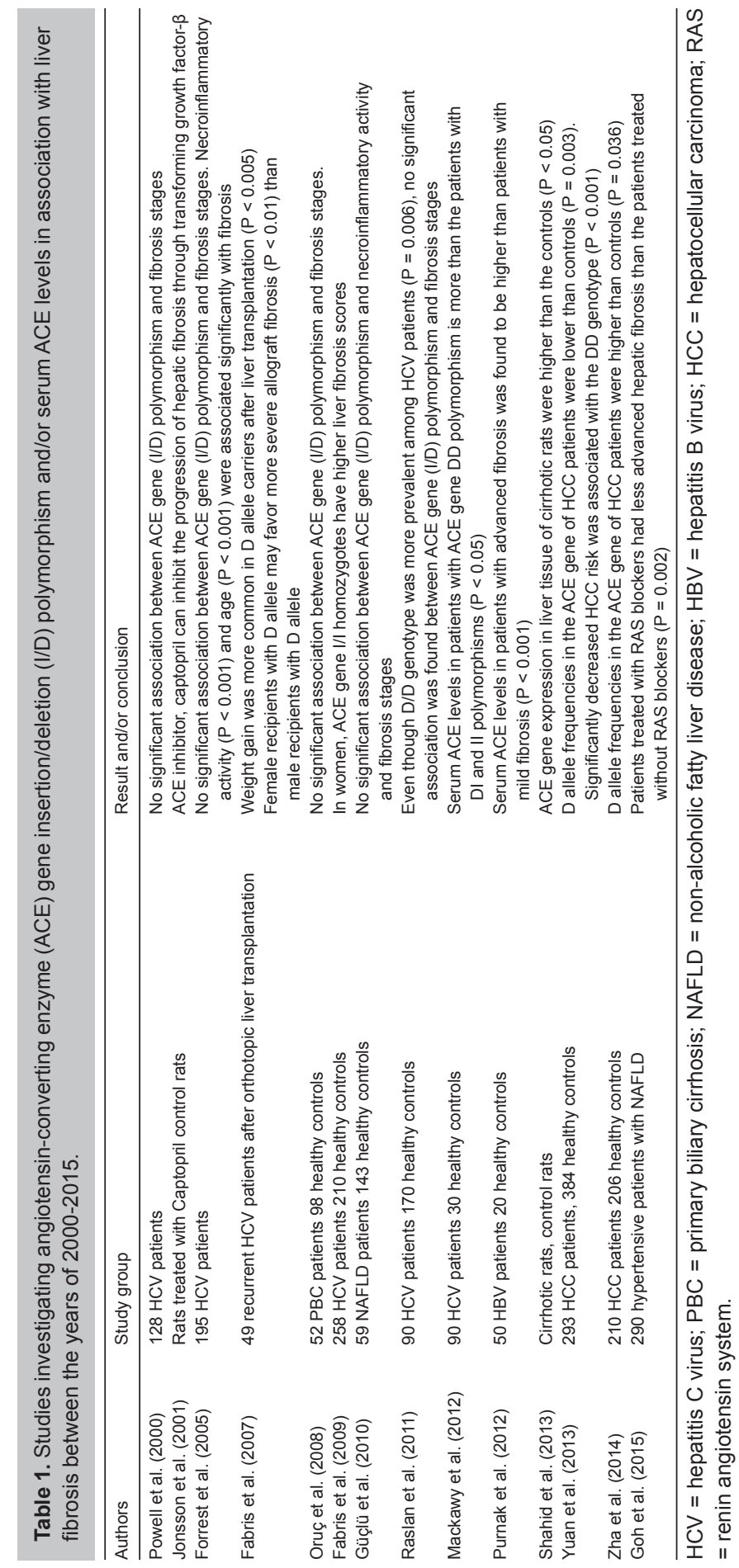




\section{Histological examination of liver biopsies}

All liver biopsies were fixed with formalin and embedded in paraffin. Sections $5 \mu \mathrm{m}$ thick were cut from each paraffin block and were stained with haematoxylin-eosin. The Ishak scoring system was used to evaluate staging and grading (Ishak et al., 1995) and all histological evaluations were carried out by the same pathologist blinded to the patients' clinical and laboratory data. Sections with overall histological activity of $\leq 6$ were classed as mild hepatitis, while sections yielding scores of 7 to 12 were classed as moderate and those with scores $>13$ severe. Fibrosis staging scores of 1 to 3 were defined as mild to moderate (Group 1) and scores of 4 to 6 were defined as advanced (Group 2). The Brunt scoring system was used to determine the extent of liver steatosis (Brunt et al., 1999) and the Child-Pugh and MELD (Model For End Stage Liver Disease) scoring systems were used to assess cirrhosis in the patients. Five clinical measures of liver disease (total bilirubin, serum albumin, PT INR [Prothrombin Time International Normalized Ratio], ascites, and hepatic encephalopathy) are important in Child-Pugh scoring to determine the severity of chronic liver disease, mainly cirrhosis. Each measure is scored (1-3) to identify patients in class $\mathrm{A}, \mathrm{B}$, or $\mathrm{C}$, where Class $\mathrm{C}$ patients have the most severe form of the disease (Child and Turcotte, 1964; Pugh et al., 1973). The MELD scoring system was also used in determining the severity of the liver disease (Kamath and Kim, 2007).

\section{Statistical analysis}

All statistical analyses were performed using SPSS 19.0 software (SPSS Inc., Chicago, IL, USA) and data distributions were determined by the Shapiro-Wilk test. All continuous variables with normal distributions were reported as mean \pm standard deviation (SD) and those without normal distribution were reported as median (minimum-maximum). Categorical variables were defined as percentages and the Pearson Chi-square test was used to assess differences between groups for categorical variables. Continuous variables were compared using an independent sample $t$-test for one group or the Mann-Whitney $U$ test for two groups. ANOVA or Kruskal-Wallis testing was used to assess differences between groups, and differences found by ANOVA to be statistically significant were further assessed using the Tukey test as a post hoc test. The Dunn's test was used as a post-hoc test following the Kruskal-Wallis test. Differences with $P \leq 0.05$ were considered statistically significant.

\section{RESULTS}

\section{Patient population}

A total of 418 patients from the western Black Sea region of Turkey were included in this study: 206 (49.3\%) HBV patients, $122(29.2 \%)$ HCV patients, $70(16.8 \%)$ NASH patients, $11(2.6 \%)$ ALD patients, 5 (1.2\%) AH patients, $3(0.7 \%)$ PBC patients, and $1(0.2 \%)$ SBC patient (Figure 1).

\section{Fibrosis scores}

Of the 418 patients, a total of 246 were diagnosed with mild to moderate fibrosis (Ishak's stage 1-3) and the rest (172 patients) had advanced liver fibrosis (Ishak's stage 4-6). 
One hundred and thirty six (66.0\%) HBV patients had liver biopsy fibrosis scores of 1-3 and 70 patients $(34.0 \%)$ had fibrosis scores of $4-6$. There was an equal proportion of patients $(61.5 \%)$ in both fibrosis groups with chronic HCV infection. Out of $70 \mathrm{NASH}$ patients, $46(65.7 \%)$ had liver biopsy fibrosis scores of 1-3 and the remaining 24 (34.3\%) patients had fibrosis scores of $4-6$. All the ALD (100\%) and most of the $\mathrm{AH}(80 \%)$ patients as well as $33.3 \%$ of the PBC patients also had advanced fibrosis. The only SBC patient also had advanced fibrosis. There were significant differences in the HAI (Hepatic Activity Index), MELD, and Child-Pugh scores between patient groups 1 (mild to moderate fibrosis; 1-3) and 2 (advanced fibrosis; 4-6) (P $<0.001$; Table 2).

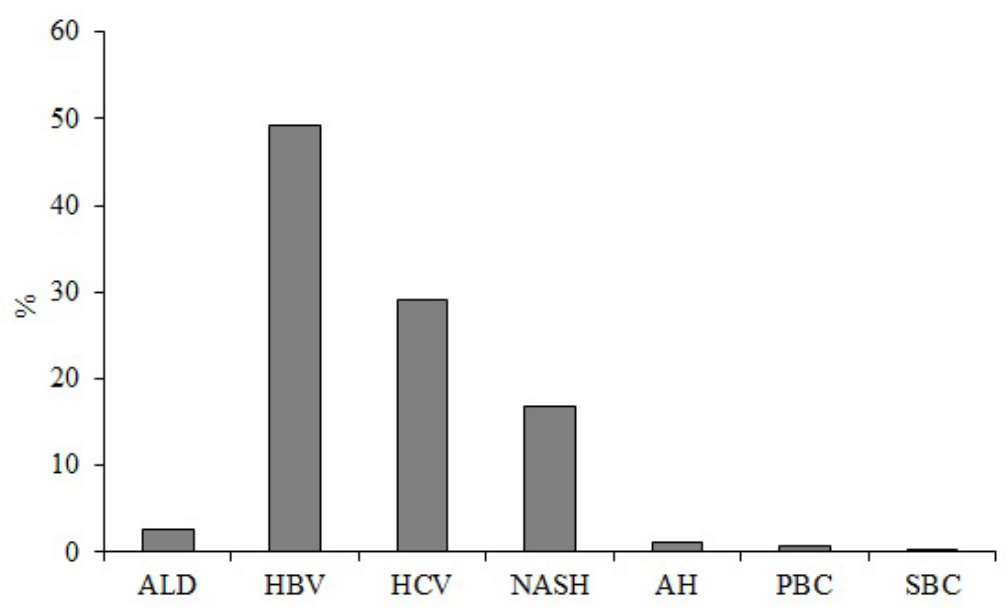

Figure 1. Distribution of patients with liver fibrosis based on etiology. ALD = alcoholic liver disease; HBV = hepatitis $B$ virus; $\mathrm{HCV}=$ hepatitis $\mathrm{C}$ virus; $\mathrm{NASH}=$ non-alcoholic steatohepatitis; $\mathrm{AH}=$ autoimmune hepatitis; $\mathrm{PBC}$ = primary biliary cirrhosis; $\mathrm{SBC}=$ secondary biliary cirrhosis. $\mathrm{N}=418$.

Table 2. Demographic, clinical, and virological data of a total of 418 patients including 206 chronic viral hepatitis B patients, 122 chronic viral hepatitis $C$ patients, 70 non-alcoholic steatohepatitis patients, 11 alcoholic liver disease patients, 5 autoimmune hepatitis patients, 3 primary biliary cirrhosis patients, and 1 secondary biliary cirrhosis patient. The patient data is divided into two groups according to liver fibrosis severity: mild to moderate fibrosis (Ishak's stage: 1-3) and advanced liver fibrosis (Ishak's stage; 4-6).

\begin{tabular}{|c|c|c|c|}
\hline & Group $1 \mathrm{~F}(1-3) \mathrm{N}=246$ & Group $2 \mathrm{~F}(4-6) \mathrm{N}=172$ & $\mathrm{P}$ \\
\hline Stage of fibrosis (No. of patients) & $1(\mathrm{~N}=26) 2(\mathrm{~N}=96) 3(\mathrm{~N}=124)$ & $4(\mathrm{~N}=56) 5(\mathrm{~N}=73) 6(\mathrm{~N}=43)$ & NA \\
\hline Age at the time of liver biopsy & $49(19-83)$ & $56(21-86)$ & $<0.001$ \\
\hline Gender & $123: 123$ & $89: 83$ & $=0.726$ \\
\hline Male:female & $50.0 \%: 50.0 \%$ & $51.7 \%: 48.3 \%$ & \\
\hline Serum ACE level (U/mL) & $36.0(8-101)$ & $38.5(7-96)$ & $=0.203$ \\
\hline ACE gene DD & $80(32.5 \%)$ & $67(39.0 \%)$ & $=0.399$ \\
\hline ID & $120(48.8 \%)$ & $76(44.2 \%)$ & \\
\hline II & $46(18.7 \%)$ & $29(16.9 \%)$ & \\
\hline $\mathrm{HAl}$ & $7(3-13)$ & $13(5-17)$ & $<0.001$ \\
\hline MELD & $7(6-15)$ & $8(6-25)$ & $<0.001$ \\
\hline Child-Pugh Scoring Class A & $244(99.2 \%)$ & $143(83.1 \%)$ & $<0.001$ \\
\hline Class B & $2(0.8 \%)$ & $22(12.8 \%)$ & \\
\hline Class C & $0(0 \%)$ & $7(4.1 \%)$ & \\
\hline
\end{tabular}

ACE = angiotensin-converting enzyme; $\mathrm{D}=$ deletion; $\mathrm{I}=$ insertion; $\mathrm{HAl}=$ hepatic activity index; MELD = model for end stage liver disease; NA = not available. 
Patient age between the two fibrosis groups also differed significantly: patients with advanced fibrosis were older than those with mild to moderate fibrosis $(P<0.001$ : Table 2 and Figure 2$)$.

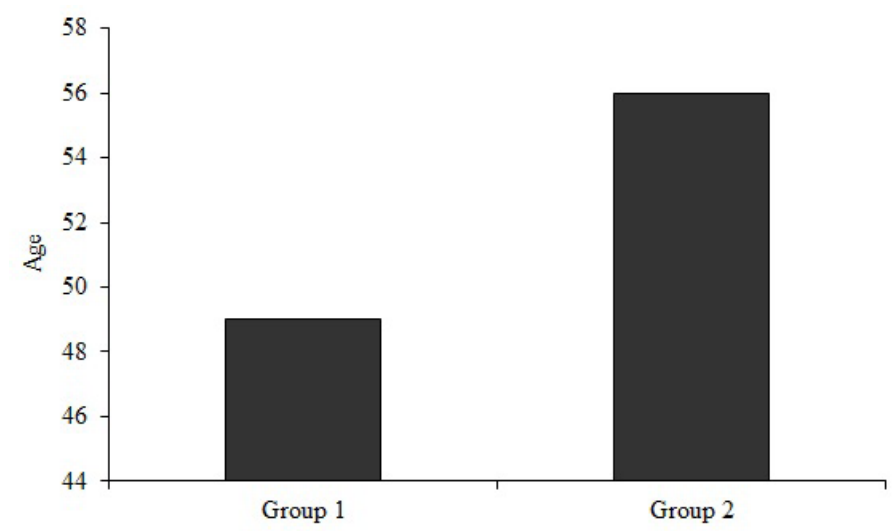

Figure 2. Patient age in the mild to moderate [Group 1 (F 1-3 according to Ishak's score)] and advanced [Group 2 ( $F$ 4-6 according to Ishak's score $)]$ liver fibrosis groups. A significant difference $(P<0.001)$ in patient age was observed between the two groups.

\section{ACE gene polymorphism}

The distributions of ACE gene I/D polymorphism in the two patient groups are shown in Table 2 and Figure 3. No significant correlation was observed between the polymorphic genotypes of ACE and the degree of fibrosis; however, ACE gene I/D polymorphism was found to be higher than II and DD polymorphisms in the HBV patients in both fibrosis groups $(49.3 \%$ in the mild to moderate fibrosis group and $50.0 \%$ in the advanced fibrosis group). In HCV and NASH patients, ACE gene I/D polymorphism was shown to be higher than II and DD polymorphisms only in the mild to moderate fibrosis group (49.2 and $45.7 \%$, respectively). The ACE gene alleles did not differ significantly between the two groups $(P=0.399$; Table 2$)$.

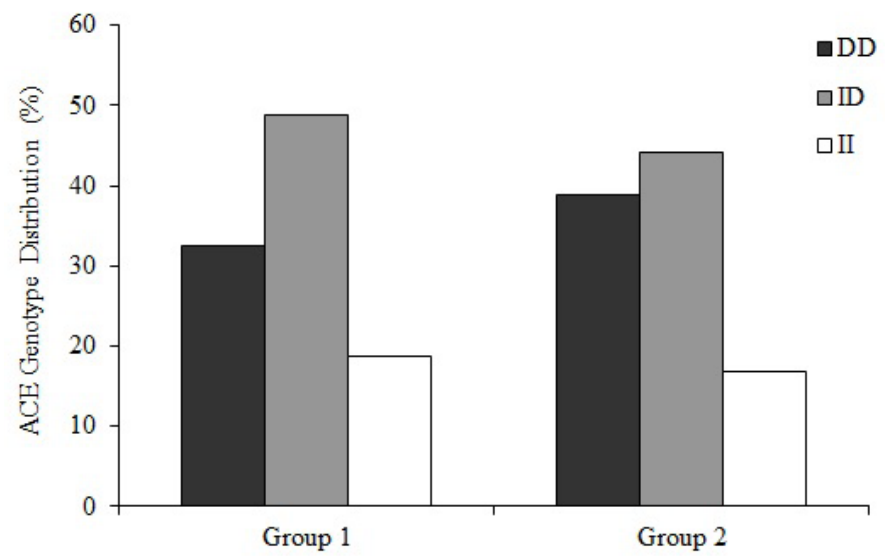

Figure 3. Distribution of ACE gene I/D polymorphism among the two fibrosis groups [Group 1 (F 1-3 according to Ishak's score), Group 2 ( $F$ 4-6 according to Ishak's score)]. No significant association between ACE gene I/D polymorphism and fibrosis severity was observed $(P=0.203)$. 


\section{Serum ACE levels}

The median (min-max) serum angiotensin-converting enzyme levels in the two patient groups are shown in Table 2. No significant correlation was observed between serum ACE levels and the degree of fibrosis $(P=0.203)$; however, there was a significant correlation between serum ACE levels and ACE gene alleles $(P<0.001$; Figure 4): serum ACE levels of patients with $D$ alleles were higher than those of patients with I alleles (44 [min 7-max 101] versus 29 [min 7-max 96]).

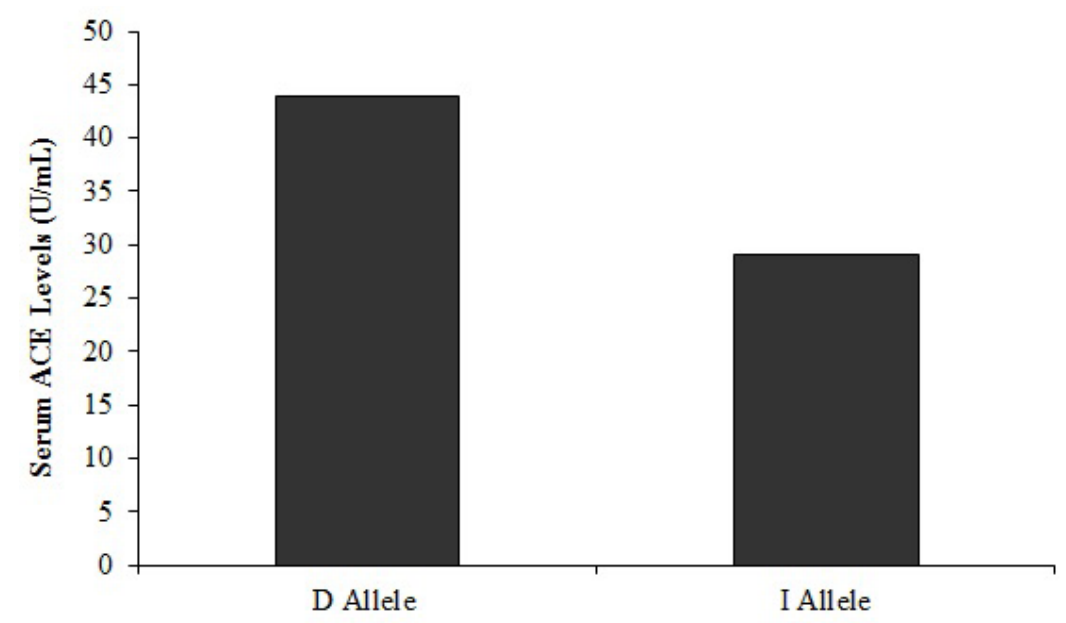

Figure 4. Serum ACE levels of patients with different ACE gene alleles. Serum ACE levels in D allele group were found to be significantly higher $(P<0.001)$ than in the I allele group: $44(7-101) \mathrm{U} / \mathrm{mL}$ versus $29(7-96) \mathrm{U} / \mathrm{mL}$.

\section{DISCUSSION}

A relationship between ACE gene expression and liver fibrosis has previously been demonstrated in experimental studies (Jonsson et al., 2001; Shahid et al., 2013). Indeed, ACE inhibitors or angiotensin receptor blockers have been shown to retard the progression of liver fibrosis (Jonsson et al., 2001; Terui et al., 2002; Kurikawa et al., 2003), suggesting that ACE gene expression may be an important marker for liver fibrosis severity. In the present study on 418 patients from western Black Sea region of Turkey, however, ACE gene I/D polymorphism and ACE gene alleles were not found to be associated with liver fibrosis severity. The ACE gene DD genotype is thought to be associated with an increased risk of rheumatic heart disease in the Saudi population (Al-Harbi et al., 2015), with nitric oxide metabolite levels and systolic blood pressure in clinically healthy Mexican men (no effect in women) (Avila-Vanzzini et al., 2015), with high altitude pulmonary edema in an Indian population (Bhagi et al., 2015), with sepsis susceptibility in Chinese patients (Yang and Zhou, 2015), with periodontal disease susceptibility in a Korean population (Kang et al., 2015), and with cancer risk in Caucasians (Zhang et al., 2014). It has been suggested that ACE gene I/D polymorphism is a genetic risk factor for Alzheimer's disease in a Chinese population (Yuan et al., 2015), while there is reportedly no association between ACE I/D gene polymorphism and a number of conditions and associated risks including type 1 diabetic nephropathy (T1DN) susceptibility and the risk of 
patients with type 1 diabetes mellitus developing T1DN in a Caucasian population (Zhou et al., 2015), chronic obstructive pulmonary disease (Ayada et al., 2014) and retinal vein occlusion (Kutlutürk et al., 2014) in a Turkish population, as well as type 2 diabetic nephropathy (T2DN) susceptibility and the risk of patients with type 2 diabetes mellitus developing T2DN in Caucasian populations (Liu et al., 2014). In a meta-analysis by Song and Lee (2014), no association was observed between ACE gene I/D polymorphism and the susceptibility to systemic sclerosis in four European studies and one study each in Asian, African American, and Latin American populations comprising a total of 837 cases and 754 controls. Similarly conflicting results have also been observed in patients with hepatic diseases: although experimental studies have demonstrated an association between liver fibrosis and ACE gene I/D polymorphism (Jonsson et al., 2001; Shahid et al., 2013), some clinical studies showed no association between ACE gene I/D polymorphism and HCV, PBC, or NAFLD (Powell et al., 2000; Forrest et al., 2005; Oruç et al., 2008; Güçlü et al., 2010; Raslan et al., 2011). This discrepancy may result from the fact that the experimental studies made use of rat liver tissue, while the clinical study analyses were done on patients' sera. Other factors may also be masking the effect of ACE gene I/D polymorphism in blood samples of patients in clinical studies.

In this study, ACE gene I/D polymorphism was assessed in patients with hepatic fibrosis and no significant association between $\mathrm{I} / \mathrm{D}$ gene polymorphism and the degree of liver fibrosis was observed. In both mild to moderate and advanced fibrosis patients, however, the frequency of ID genotypes were higher than the DD and II genotypes. In agreement with our findings, Forrest et al. (2005) investigated the relationship between the four RAS (Renin-Angiotensin System) gene polymorphisms including ACE I/D gene polymorphism and the liver fibrosis stage in HCV patients and no correlation between these four RAS gene polymorphisms and the development of fibrosis in chronic HCV infection was observed. Fabris et al. (2007) suggested a relationship between gender and ACE gene I/D polymorphism: in a study performed with 49 recurrent HCV patients that had undergone orthotopic liver transplantation, female recipients with the $\mathrm{D}$ allele were reported to have more severe fibrosis than male recipients with the D allele. Fabris et al. (2009) also reported that among women, ACE I/I homozygote patients had higher liver fibrosis scores than ACE D/D homozygote and ACE I/D heterozygote patients. In this study, no association was observed between gender and liver fibrosis.

In the study by Raslan et al. (2011), no significant association was observed between ACE gene (I/D) polymorphism and fibrosis stage; however, the DD genotype was more prevalent in HCV patients than in the control subjects. In a Chinese population, Yuan et al. (2013) demonstrated the ACE gene D allele frequency in patients with $\mathrm{HCC}$ to be lower than in healthy controls. Zha et al. (2014) also conducted a study on HCC patients, and contrary to the findings reported by Yuan et al. (2013), found $D$ allele frequencies to be higher in HCC patients than in the control subjects.

In a recent study, NAFLD patients treated with RAS blockers were reported to have less advanced hepatic fibrosis (Goh et al., 2015). In the present study, the allele frequencies among patients with mild to moderate fibrosis ( $N=246, F: 1-3$ according to Ishak's score) were DD: $32.5 \%$, ID: $48.8 \%$, and II: $18.7 \%$; while in the advanced fibrosis group ( $N=172, F: 4-6$ according to Ishak's score) the frequencies were DD: $39.0 \%$, ID: $44.2 \%$, and II: $16.9 \%$.

It has been demonstrated that serum ACE levels are higher in chronic liver disease, indicating that ACE activity may be an important marker of liver disease severity (Schweisfurth and Wernze, 1979; Sakata et al., 1991); however, Forrest et al. (2005) found no correlation between increased serum ACE activity and ACE genotype in HCV patients. In this study, no significant 
correlation was observed between serum ACE levels and liver fibrosis stage of patients; however, there was a significant difference between the serum ACE levels of patients with different ACE gene alleles $(P<0.001)$ : serum ACE levels of patients with $D$ alleles were higher than those in patients with I alleles [(44 (min 7-max 101) versus 29 (min 7-max 96)]. Mackawy et al. (2012) also reported an association between serum ACE levels and ACE gene alleles and furthermore reported serum ACE levels to be higher in HCV patients with DD alleles than in those with ID and II alleles. Purnak et al. (2012) identified a relationship between serum ACE levels and liver fibrosis stage in patients with HBV infection and found serum ACE levels of patients to be significantly elevated compared with those in healthy controls. In the present study, no significant difference was observed between serum ACE levels among the fibrosis groups; however, HAI, MELD, and Child-Pugh scores differed significantly $(P<0.001)$ between the two groups. The previously reported enhancement in serum ACE levels may relate to liver reserve capacity rather than ACE gene I/D polymorphism.

Apart from the genetic factors, age at the time of liver biopsy also differed significantly between the mild to moderate and advanced fibrosis groups in our study, an observation previously also reported for HCV patients (Forrest et al., 2005). One of the strengths of this study is that it was designed to assess the possible effects of ACE gene I/D polymorphism in a large group of hepatic patients with a variety of diseases (HBV, HCV, NASH, ALD, AH, $\mathrm{PBC}$, and SBC). ACE gene I/D polymorphism and serum ACE levels were analyzed in 418 samples from patients with hepatic diseases and with different stages of liver fibrosis with different etiologies. A potential limitation of the study, on the other hand, may be the fact that the different hepatic disease groups did not consist of equal numbers of patients. In summary, no significant association between ACE gene (I/D) polymorphism and hepatic fibrosis was observed in this study, indicating that ACE gene (I/D) polymorphism cannot be considered a marker of liver fibrosis severity and/or that assessing ACE gene (I/D) polymorphism is not an alternative to liver biopsy. Future research into this field should include large-scale studies comparing different races as well as environmental factors such as alcohol and tobacco consumption to more accurately define the effects of ACE I/D polymorphism on hepatic fibrosis.

\section{Conflicts of interest}

The authors declare no conflict of interest.

\section{REFERENCES}

Al-Harbi KM, Almuzaini IS, Morsy MM, Abdelaziz NA, et al. (2015). Angiotensin-converting enzyme gene insertion/deletion polymorphism in Saudi patients with rheumatic heart disease. Saudi Med. J. 36: 176-180.

Avila-Vanzzini N, Posadas-Romero C, Gonzalez-Salazar MD, Maass-Iturbide C, et al. (2015). The ACE I/D polymorphism is associated with nitric oxide metabolite and blood pressure levels in healthy Mexican men. Arch. Cardiol. Mex. 85: 105-110.

Ayada C, Toru U, Genç O, Yerlikaya A, et al. (2014). Evaluation of whether the ACE gene I/D polymorphism constitutes a risk factor for chronic obstructive pulmonary disease in the Turkish population. Genet. Mol. Res. 13: 10427-10433.

Bhagi S, Srivastava S, Tomar A, Bala Singh S, et al. (2015). Positive association of D allele of ACE gene with high altitude pulmonary edema in Indian population. Wilderness Environ. Med. 26: 124-132.

Brunt EM, Janney CG, Di Bisceglie AM, Neuschwander-Tetri BA, et al. (1999). Nonalcoholic steatohepatitis: a proposal for grading and staging the histological lesions. Am. J. Gastroenterol. 94: 2467-2474.

Child CG and Turcotte JG (1964). Surgery and portal hypertension. Major Probl. Clin. Surg. 1: 1-85.

Cushman DW and Cheung HS (1971). Spectrophotometric assay and properties of the angiotensin-converting enzyme of rabbit lung. Biochem. Pharmacol. 20: 1637-1648.

Fabris C, Toniutto P, Bitetto D, Minisini R, et al. (2007). Sex-related influence of angiotensin-converting enzyme polymorphisms 
on fibrosis progression due to recurrent hepatitis C after liver transplantation. J. Gastroenterol. 42: 543-549.

Fabris C, Smirne C, Fangazio S, Toniutto P, et al. (2009). Influence of angiotensin-converting enzyme I/D gene polymorphism on clinical and histological correlates of chronic hepatitis C. Hepatol. Res. 39: 795-804.

Forrest EH, Thorburn D, Spence E, Oien KA, et al. (2005). Polymorphisms of the renin-angiotensin system and the severity of fibrosis in chronic hepatitis $C$ virus infection. J. Viral. Hepat. 12: 519-524.

Goh GB, Pagadala MR, Dasarathy J, Unalp-Arida A, et al. (2015). Renin-angiotensin system and fibrosis in non-alcoholic fatty liver disease. Liver Int. 35: 979-985.

Güçlü M, Yakar T and Serin E (2010). Angiotensin converting enzyme gene (I/D) polymorphism and nonalcoholic fatty liver disease. Eur. J. Gen. Med. 7: 136-142.

Ishak K, Baptista A, Bianchi L, Callea F, et al. (1995). Histological grading and staging of chronic hepatitis. J. Hepatol. 22: 696-699.

Jonsson JR, Clouston AD, Ando Y, Kelemen LI, et al. (2001). Angiotensin-converting enzyme inhibition attenuates the progression of rat hepatic fibrosis. Gastroenterology 121: 148-155.

Kamath PS and Kim WR (2007). The model for end-stage liver disease (MELD). Hepatology 45: 797-805.

Kang SW, Han SY, Lim SB, Cho KB, et al. (2015). ACE insertion/deletion polymorphism is associated with periodontal disease in Korean population. Arch. Oral Biol. 60: 496-500.

Kurikawa N, Suga M, Kuroda S, Yamada K, et al. (2003). An angiotensin II type 1 receptor antagonist, olmesartan medoxomil, improves experimental liver fibrosis by suppression of proliferation and collagen synthesis in activated hepatic stellate cells. Br. J. Pharmacol. 139: 1085-1094.

Kutlutürk I, Karagöz A, Bezgin T, Oduncu V, et al. (2014). Relationship between angiotensin I-converting enzyme insertion/ deletion gene polymorphism and retinal vein occlusion. Thromb. J. 12: 17.

Li YS, Ni SY, Meng Y, Shi XL, et al. (2013). Angiotensin II facilitates fibrogenic effect of TGF- $\beta 1$ through enhancing the downregulation of BAMBI caused by LPS: a new pro-fibrotic mechanism of angiotensin II. PLoS One. 8: e76289.

Lieberman J (1975). Elevation of serum angiotensin-converting-enzyme (ACE) level in sarcoidosis. Am. J. Med. 59: $365-372$.

Liu G, Zhou TB, Jiang Z and Zheng D (2014). Association of ACE I/D gene polymorphism with T2DN susceptibility and the risk of T2DM developing into T2DN in a Caucasian population. J. Renin. Angiotensin Aldosterone Syst. 16: $165-171$.

Mackawy AMH, Badawy MEH and Megahed OAEY (2012). Angiotensin converting enzyme (ACE D/I) polymorphism and its relation to liver fibrosis progression in Egyptian patients with chronic hepatitis C virus infection. Egyp. J. Med. Hum. Gen. 13: 291-299.

Oruç N, Lamb J, Whitcomb DC and Sass DA (2008). The ACE gene I/D polymorphism does not affect the susceptibility to or prognosis of PBC. Turk. J. Gastroenterol. 19: 250-253.

Powell EE, Edwards-Smith CJ, Hay JL, Clouston AD, et al. (2000). Host genetic factors influence disease progression in chronic hepatitis C. Hepatology. 31: 828-833.

Pugh RN, Murray-Lyon IM, Dawson JL, Pietroni MC, et al. (1973). Transection of the oesophagus for bleeding oesophageal varices. Br. J. Surg. 60: 646-649.

Purnak T, Beyazit Y, Oztas E, Yesil Y, et al. (2012). Serum angiotensin-converting enzyme level as a marker of fibrosis in patients with chronic hepatitis B. J. Renin Angiotensin Aldosterone Syst. 13: 244-249.

Raslan HM, Amr KS, Elhosary YA, Ezzat WM, et al. (2011). Possible role of angiotensin-converting enzyme polymorphism on progression of hepatic fibrosis in chronic hepatitis C virus infection. Trans. R. Soc. Trop. Med. Hyg. 105: 396-400.

Rigat B, Hubert C, Alhenc-Gelas F, Cambien F, et al. (1990). An insertion/deletion polymorphism in the angiotensin I-converting enzyme gene accounting for half the variance of serum enzyme levels. J. Clin. Invest. 86: 1343-1346.

Rigat B, Hubert C, Corvol P and Soubrier F (1992). PCR detection of the insertion/deletion polymorphism of the human angiotensin converting enzyme gene (DCP1) (dipeptidyl carboxypeptidase 1). Nucleic Acids Res. 20: 1433.

Sakata T, Takenaga N, Endoh T, Wada O, et al. (1991). Diagnostic significance of serum angiotensin-converting enzyme activity in biochemical tests with special reference of chronic liver diseases. Jpn. J. Med. 30: 402-407.

Schweisfurth $\mathrm{H}$ and Wernze $\mathrm{H}$ (1979). Changes of serum angiotensin 1 converting enzyme in patients with viral hepatitis and cirrhosis. Acta Hepatogastroenterol. 26: 207-210.

Shahid SM, Fatima SN, Mahboob T (2013). Angiotensin converting enzyme (ACE) gene expression in experimentally induced liver cirrhosis in rats. Pak. J. Pharm. Sci. 26: 853-857.

Song GG and Lee YH (2014). Angiotensin-converting enzyme insertion/deletion polymorphism and susceptibility to systemic sclerosis: a meta-analysis. Genet. Mol. Res. 13: 8174-8183.

Terui Y, Saito T, Watanabe H, Togashi H, et al. (2002). Effect of angiotensin receptor antagonist on liver fibrosis in early stages of chronic hepatitis C. Hepatology 36: 1022.

Yang CH and Zhou TB (2015). Association of the ACE I/D gene polymorphism with sepsis susceptibility and sepsis progression. J. Renin. Angiotensin Aldosterone Syst. Feb 3. [Epub Ahead of Print]. 
Yuan F, Zhang LS, Li HY, Liao M, et al. (2013). Influence of angiotensin I-converting enzyme gene polymorphism on hepatocellular carcinoma risk in China. DNA Cell Biol. 32: 268-273.

Yuan Y, Piao JH, Ma K and Lu N (2015). Angiotensin-converting enzyme gene insertion-deletion polymorphism is a risk marker for Alzheimer's disease in a Chinese population: a meta-analysis of case-control studies. J. Neural. Transm. 122: 1105-1113.

Zha Y, Gan P, Liu Q and Tan J (2014). Relationship between polymorphism of angiotensin-converting enzyme gene insertion/ deletion and risk of hepatocellular carcinoma in a Chinese Dai population. J. Renin Angiotensin Aldosterone Syst. 16: 695-699.

Zhang K, Cheng D, Yi L, Shi H, et al. (2014). Association between angiotensin I-converting enzyme gene polymorphism and susceptibility to cancer: a meta analysis. Int. J. Clin. Exp. Pathol. 7: 6291-6300.

Zhou TB, Guo XF, Jiang Z and Li HY (2015). Relationship between the ACE I/D gene polymorphism and T1DN susceptibility/risk of T1DM developing into T1DN in the Caucasian population. J. Renin Angiotensin Aldosterone Syst. [Epub Ahead of Print]. 